\title{
Abuso Sexual Infanto-Juvenil: A Atuação do Programa Sentinela na Cidade de Blumenau/SC
}

Children's sexual abuse: the performance

of the sentinela program in Blumenau / SC

Abuso sexual infanto-juvenil: la actuación del programa sentinela en la ciudad de Blumenau/SC
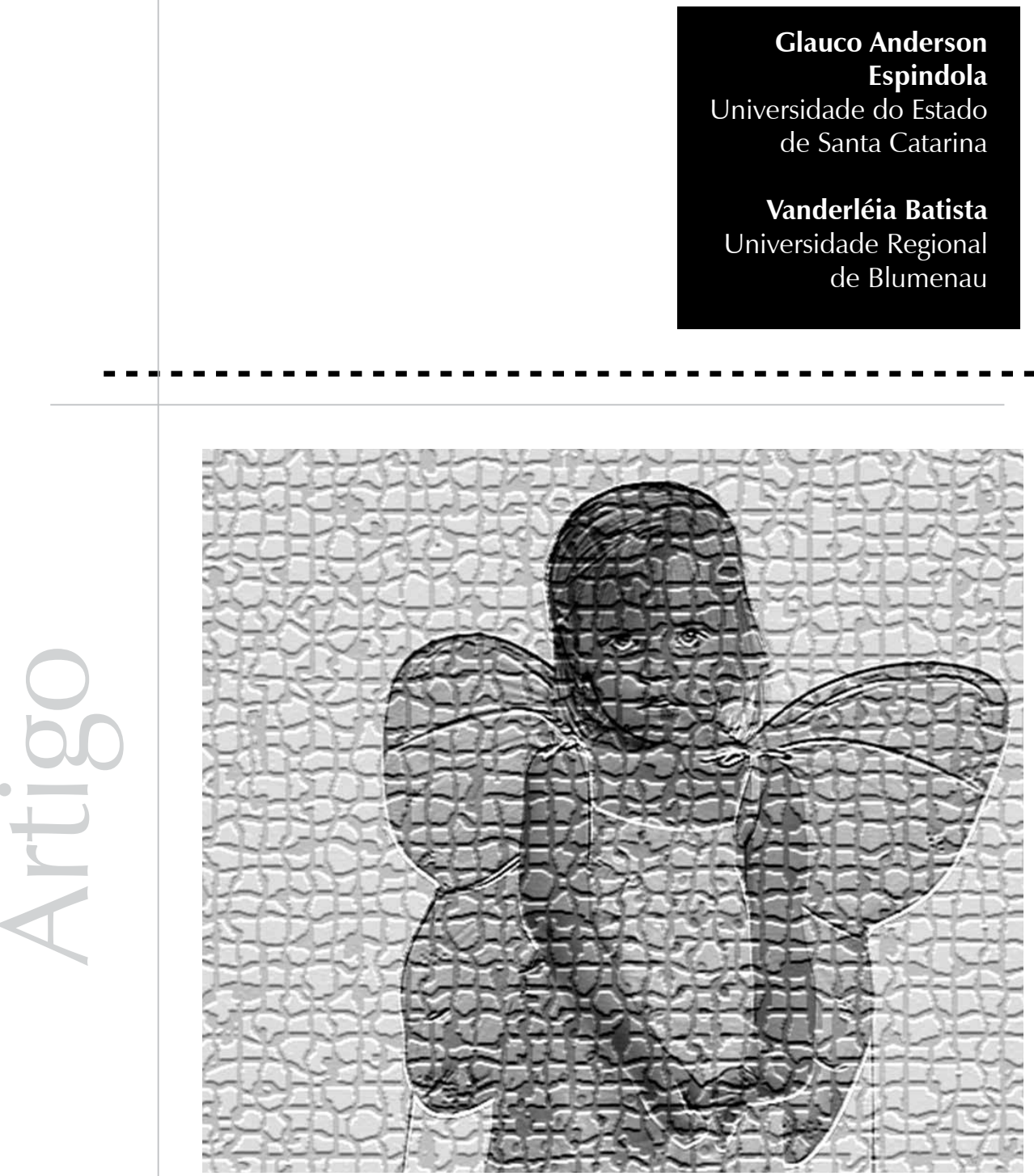
Resumo: A violência sexual contra crianças e adolescentes é um problema de saúde pública que exige uma intervenção adequada. O presente estudo teve como objetivo identificar a atuação do Programa Sentinela, da cidade de Blumenau/SC, diante da violência sexual infanto-juvenil e mapear seus fatores de assistência e de vulnerabilidade. A metodologia empregada foi a análise documental das intervenções realizadas pelo programa. O estudo foi composto por 30 prontuários relativos a todas as crianças e adolescentes em situação de violência sexual atendidos pelo Sentinela que foram desligados do programa no segundo semestre de 2009. Os resultados apontam o programa como uma ferramenta contra a violência sexual infanto-juvenil, mas, da mesma forma, demonstram que ele necessita de melhorias. Entre os fatores de assistência, observouse a credibilidade do Sentinela, o atendimento aos cuidadores das crianças e adolescentes, a variedade de intervenções e a articulação entre aspectos psicológicos, sociais e legais. Verificou-se, por outro lado, a falta de comunicação entre as instituições para articular as medidas de proteção necessárias, o não planejamento das intervenções, a não realização de intervenção com o autor da violência e a ausência de informações em alguns prontuários como fatores de vulnerabilidade.

Palavras-chave: Abuso da Criança. Abuso sexual. Agressões sexuais. Políticas públicas.

Abstract: The sexual violence against children and adolescents is a public health problem that demands an adequate intervention. The present study aims to identify the performance of the Sentinela Program of Blumenau/SC due to sexual violence against children and adolescents. The study presents the mapping of service and the vulnerability factors in the program's resource network. The methodology used in the research was the documentary analysis of the interventions that were performed by the program. The study was composed by 30 medical records for all children and adolescents in situations of sexual violence treated at the Sentinela that have been disconnected from the program in the second semester of 2009. The results revealed that the Sentinela Program is a tool against sexual violence against children and adolescents but at the same time they showed that the program needs improvement. Among the assistance factors observed were the credibility of the Sentinela, the treatment with children and adolescents' parents, the variety of interventions and the relationship among psychological, social and legal aspects. On the other hand the vulnerability factors were the lack of communication among institutions to articulate the necessary protection measures, badly planned interventions, failure to complete the intervention with the perpetrator of the violence and the lack of information in some records.

Keywords: Child abuse. Abuse sexual. Sex offenses. Public policies.

Resumen: La violencia sexual contra niños y adolescentes es un problema de salud pública que exige una intervención adecuada. El presente estudio tuvo como objetivo identificar la actuación del Programa Sentinela, de la ciudad de Blumenau/SC, ante la violencia sexual infanto- juvenil; $y$, mapear sus factores de asistencia y de vulnerabilidad. La metodología empleada fue el análisis documental de las intervenciones realizadas por el Programa. El estudio estuvo compuesto de 30 historias clínicas relativas a todos los niños y adolescentes en situación de violencia sexual atendidos por el Sentinela que fueron retirados del programa en el segundo semestre de 2009. Los resultados apuntan el Programa Sentinela como una herramienta contra la violencia sexual infanto- juvenil, pero, de la misma forma, demuestran que el Programa necesita mejorías. Entre los factores de asistencia se observó la credibilidad del Sentinela, la atención a los cuidadores de los niños y adolescentes, la variedad de intervenciones y la articulación entre aspectos psicológicos, sociales y legales. Se verificó, por otro lado, la falta de comunicación entre las instituciones para articular las medidas de protección necesarias; la no planificación de las intervenciones, la no realización de intervención con el autor de la violencia; y, la ausencia de informaciones, como, por ejemplo, sobre factores de vulnerabilidad, en algunas historias clínicas.

Palabras clave: Abuso de niños. Abuso sexual. Delitos sexuales. Políticas Públicas.

A violência sexual infanto-juvenil é um fenômeno prevalente desde a antiguidade, que, atualmente, devido aos altos índices de incidência e ao seu impacto negativo no desenvolvimento das crianças e adolescentes, se tornou uma questão de saúde pública. Tal fato refletiu a necessidade de se criar serviços especializados e capacitados que possam prestar atendimento a crianças e adolescentes que sofreram abuso sexual. Nesse sentido, o objetivo da presente pesquisa é identificar os mecanismos de funcionamento do Programa Sentinela, da cidade de Blumenau/SC, suas estratégias e técnicas de enfrentamento da violência sexual, bem como identificar os fatores de assistência e de vulnerabilidade do programa, fornecendo subsídios que possibilitem sua qualificação. 
Segundo Furniss (1993), os fatores que influenciam o impacto da violência sexual são a idade de início do abuso, a duração do abuso, o grau de violência ou da ameaça de violência, a diferença de idade entre a pessoa que cometeu o abuso e a criança que sofreu o abuso, o vínculo entre o autor da violência e a criança e a ausência de características parentais protetoras.
A violência sexual é definida pela Organização Mundial da Saúde (World Health Organization, 2003) como qualquer atividade sexual, tentativa de obtenção do ato sexual, ações de tráfico de mulheres para prostituição ou comentários sexuais indesejáveis realizados por qualquer pessoa conhecida ou desconhecida da vítima pelo uso de coerção, de ameaças ou de força física. Tal conceito denota a não limitação da violência sexual ao ato sexual em si, e inclui desde a prática de carícias, a manipulação de genitália, mama ou ânus, a exploração sexual, o voyeurismo, a pornografia, o exibicionismo, até o ato sexual, com ou sem penetração.

O abuso sexual infanto-juvenil, da mesma forma, não se restringe a uma prática realizada por um adulto em relação a uma criança, mas abrange qualquer prática sexual realizada por uma pessoa em relação a outra com menor nível de desenvolvimento psicossexual. Assim sendo, Arboleta e Duarte (2005) afirmam que o contato sexual entre um adolescente e uma criança menor pode ser considerado abusivo quando há uma diferença significativa de idade, de desenvolvimento ou de tamanho, que não permita ao menor ter condições de dar consentimento consciente para o ato.

Em relação à epidemiologia da violência sexual, estudos realizados em diferentes partes do mundo sugerem uma prevalência do abuso sexual infanto-juvenil de $7 \%$ a $36 \%$ entre as meninas, e de 3\% a 29\% entre os meninos (World Health Organization, 2003). De acordo com dados da Associação Brasileira de Proteção à Infância e à Adolescência (ABRABIA, 2002), estima-se que, no Brasil, 165 crianças sofram abuso sexual por dia ou 7 a cada hora. Na cidade de Blumenau/ SC, a realidade não é diferente. Conforme a Delegacia de Proteção à Mulher, à Criança e ao Adolescente (DPPMCA), entre janeiro de 2006 e agosto de 2008, foram registradas 104 ocorrências de abuso sexual contra crianças e adolescentes (esses dados se restringem aos abusos realizados por maiores de 18 anos).
Entretanto, esses números representam uma dimensão parcial do fenômeno, uma vez que muitos casos de abuso sexual infantojuvenil não são denunciados, devido tanto a sentimentos de vergonha e medo da criança ou do adolescente quanto ao sigilo intrafamiliar, como, por exemplo, nos casos em que mães encobrem a violência dos maridos, à relutância de alguns profissionais em reconhecer e relatar o abuso e à insistência de tribunais por regras estritas de evidência (Furniss, 1993).

O impacto da violência sexual é complexo e variado, e envolve consequências físicas, psicobiológicas, psicológicas e sociais. Segundo Habigzang, Koller, Azevedo e Machado (2006), crianças ou adolescentes em situação de violência sexual podem desenvolver quadros de depressão, transtornos de ansiedade, alimentares, dissociativos, hiperatividade e déficit de atenção, transtorno de personalidade borderline e transtorno do estresse pós-traumático; essas crianças e adolescentes podem igualmente apresentar crenças disfuncionais relacionadas com a situação abusiva.

No entanto, o abuso sexual afeta o desenvolvimento de crianças e adolescentes de maneiras diferentes. Em alguns casos, a criança ou o adolescente pode apresentar efeitos mínimos ou nenhum efeito aparente, e, em outros, podem ocorrer graves problemas emocionais, sociais e/ou psiquiátricos (Saywitz, Mannarino, Berliner, \& Cohen, 2000). Segundo Furniss (1993), os fatores que influenciam o impacto da violência sexual são a idade de início do abuso, a duração do abuso, o grau de violência ou da ameaça de violência, a diferença de idade entre a pessoa que cometeu o abuso e a criança que sofreu o abuso, o vínculo entre o autor da violência e a criança e a ausência de características parentais protetoras. Além desses fatores, Habigzang et. al. ressaltam a influência das características pessoais da criança ou do adolescente, da rede de apoio social e dos recursos financeiros. 
Sendo assim, toda a rede de apoio social da criança ou do adolescente, que inclui, conforme Habigzang, Azevedo, Koller e Machado (2006), os órgãos de proteção à criança e ao adolescente, tais como os Conselhos de Direito, Conselhos Tutelares, Promotoria e Juizado da Infância e Adolescência e demais instituições como escolas, postos de saúde, hospitais e abrigos, entre outras, irá influir no impacto da violência sexual. Como denota Furniss (1993), uma intervenção profissional equivocada pode levar a um dano secundário e à revitimização das crianças que sofreram violência sexual, podendo, de tal modo, ocasionar um dano psicológico adicional à criança. Uma rede de apoio social articulada, portanto, constituída por profissionais competentes e qualificados, que possibilite um ambiente protetor e afetivo à criança e ao adolescente e evite a sua revitimização, é de extrema importância na minimização dos efeitos negativos da violência sexual.

Nesse sentido, o abuso sexual infanto-juvenil exige a intervenção coordenada de uma rede de instituições, e inclui aspectos médicos, legais e psicossociais. Por conseguinte, Furniss afirma que os profissionais envolvidos com as questões do abuso sexual infanto-juvenil precisam integrar, em uma abordagem global, aspectos normativos e de saúde mental. Assim, os terapeutas podem ter de confiar no apoio das agências legais para a terapia, tanto quanto os profissionais da lei podem ter que compreender a dimensão psicológica do abuso sexual. Além disso, os aspectos jurídicos e clínicos devem ser conduzidos de uma forma coordenada, para que a criança ou o adolescente não seja revitimizada pela repetição de questionamentos desnecessários e para que a informação não seja perdida ou distorcida. Realizar uma comunicação ajustada para a idade ou para a compreensão da criança e documentar todas as informações, incluindo os estados emocionais da criança ou do adolescente e de sua família são também fatores relevantes (World Health Organization, 2003).

Destaca-se, todavia, que a compreensão do nível de risco de danos no ambiente da criança ou do adolescente e o subsequente planejamento de segurança são os primeiros passos na avaliação de casos de abuso sexual (Saunders, Berliner, \& Hanson, 2004). Uma vez que muitas crianças e adolescentes abusados sexualmente continuam a viver com o autor da violência ou em famílias onde a violência doméstica ocorre, determinar um ambiente seguro para a criança ou adolescente em situação de violência sexual é uma prioridade. No mais, deve-se preparar adequadamente a criança ou adolescente antes de ela/elecomparecer ao tribunal para testemunhar (Arboleta et al., 2005).

Nas intervenções terapêuticas, o acolhimento é o primeiro passo para um tratamento eficiente. Neste, conforme Pfeiffer e Salvagni (2005), é preciso que se crie um bom vínculo, explicando sempre o que será feito e o porquê de isso ser feito, sem que se prometa o que não se pode cumprir, pois a escuta da história da criança ou adolescente, livre de preconceitos, sem interrupções ou solicitações de detalhamentos desnecessários, vai demonstrar respeito a quem foi desrespeitado no que tem de mais precioso, que é seu corpo, sua imagem e seu amor-próprio.

Além disso, é preciso considerar a singularidade do impacto da violência sexual, tornando-se necessário, segundo Saywitz et. al. (2000) realizar tratamentos em diferentes modalidades (individual, familiar, grupo, farmacológico) e em diferentes níveis de cuidados, para diferentes crianças ou para a mesma criança em diferentes tempos. Assim, um princípio básico de toda a prática clínica é a realização de uma avaliação inicial da criança ou do adolescente em situação de violência sexual. De tal modo, o plano de tratamento deve ser desenvolvido com base nos resultados da 
avaliação, verificando-se as necessidades de cada criança ou adolescente bem como de suas famílias. Da mesma forma, a avaliação é um componente integral do processo contínuo do tratamento. É preciso realizar avaliações periódicas da criança ou do adolescente, para acompanhar o tratamento e identificar os problemas emergentes (Saunders, Berliner, \& Hanson, 2004).

$\mathrm{Na}$ escolha do tipo de atendimento, a literatura aponta os atendimentos psicológicos psicossociais e psicoeducativos, sendo a escolha dependente da avaliação inicial da criança ou do adolescente. Vale destacar que as crianças e adolescentes que aparentemente não apresentam nenhum sintoma podem beneficiar-se do tratamento psicoeducativo para a prevenção de futuras vitimizações e para verificação, durante um período de tempo, de consequências que poderiam estar ainda latentes (Saywitz et. al. 2000).

Com relação ao tempo de intervenção clínica, segundo Habigzang (2006), este pode variar de acordo com o referencial teórico que fundamenta a intervenção e os fatores relacionados com a história de abuso e as consequências desse abuso para a criança ou adolescente. Ressalta-se, no entanto, que o fator de maior relevância na intervenção do abuso sexual infanto-juvenil não é o tempo de duração do tratamento, mas o tempo de duração de seus efeitos, pois um tratamento com maior duração dos efeitos não apenas produz melhora dos sintomas psicológicos mas também tem melhores resultados na suspensão ou até mesmo na reversão dos efeitos psicobiológicos do abuso sexual infanto-juvenil (Cohen, Knudsen, \& Mannarino, 2005).

No que se refere à modalidade terapêutica, Habigzang (2006) afirma que diversas modalidades podem ser utilizadas como recursos para a intervenção, havendo estudos e pesquisas que apontam os efeitos positivos no tratamento do abuso sexual das modalidades individual, grupal e familiar. Todavia, é de notável importância observar que a modalidade grupal tem apresentado melhores resultados na redução da ansiedade, de sintomas depressivos e de sentimentos de culpabilização e diferenciação (Mcgain \& Mckinzey, 1995; Seixas, 1999; Habigzang, 2006), uma vez que prioriza um espaço onde as crianças e os adolescentes podem dividir suas experiências e sentimentos com alguém que passou pela mesma situação que eles. Conforme Habigzang, o grupo tem a função de oferecer apoio e alívio emocional para a criança ou adolescente, fazendo com que eles não se sintam sozinhos. Além disso, através do relato de sentimentos referentes ao abuso, da discussão das crenças de culpa pela experiência abusiva e do desenvolvimento de habilidades preventivas a outras situações abusivas, propicia-se a modificação do autoconceito das crianças e dos adolescentes em situação de abuso sexual de autodesprezo para autovalorização.

Outra consideração especial em casos de abuso sexual é a postura dos cuidadores relativa à acusação da violência. Geralmente, os pais entram ou trazem os filhos para tratamento devido à recomendação ou à exigência das autoridades. Em alguns casos, eles podem estar em busca de tratamento devido apenas ao mandato judicial, podendo contestar as alegações de abuso ou minimizar o impacto negativo sobre a criança ou adolescente. Desse modo, a avaliação da percepção parental e do estágio de prontidão para a mudança é um ingrediente central para desenvolver um plano de tratamento significativo (Saunders, Berliner \& Hanson, 2004). Saywitz et. al. (2000) também acrescentam que a melhora da consequência da violência sexual depende não apenas da eficácia do tratamento e das condições da criança ou do adolescente mas também da atuação dos adultos de quem a criança depende. 
É de extrema importância que o abusador receba alguma forma de tratamento. Furniss compara a pessoa que abusa sexualmente com um alcoolista, sendo o álcool comparado à criança ou ao adolescente. Dessa forma, ele destaca que os autores de violência sexual necessitam de uma prolongada terapia, em que a pré-condição é a admissão inicial do ato abusivo. No mais, o autor afirma que precisamos acreditar que as pessoas que cometem abuso sexual queiram parar de abusar, mas ainda não devemos acreditar que elas não irão recair no abuso futuramente, pois, assim como em outras formas de adição, essas pessoas correm o risco de recaída se não evitarem situações de alto risco. Outrossim, o autor da violência não deve ser visto apenas como um abusador, mas como um ser humano que cometeu um erro e que precisa de ajuda; portanto, a terapia com o autor da violência, embora seja de extrema complexidade, é necessária, até mesmo como uma forma de compreensão da violência sexual e de prevenção da ocorrência de novos abusos.

Para finalizar, é importante destacar a existência de poucos estudos controlados que avaliam os resultados de tratamentos com crianças e adolescentes em situação de violência sexual (Saywitz et. al., 2000), fato que se agrava na literatura brasileira (Ferreira \& Gonçalves, 2002). Além disso, a maior parte das pesquisas sobre estratégias de atendimento aos casos de abuso sexual infantil focaliza poucos aspectos do atendimento, abordando, sobretudo, o processo de diagnóstico, cuja figura central é o médico, o que reflete a ausência de uma visão integral do atendimento (Alzuguir, Assis, \& Souza, 2002). Conforme Pereda, Polo, Grau, Navales e Martínez (2007), tal fato é consequência da falta, na maioria das ocasiões, de um dano físico visível, e da inexistência de um conjunto de sintomas psicológicos que permitam a detecção e o diagnóstico da violência sexual. Por outro lado, acrescenta-se a isso o pacto de silêncio que cerca esses fatos e o escândalo social que envolve as pessoas em questão.
Como podemos notar, embora seja relevante realizar novas pesquisas sobre formas de intervenção com crianças e adolescentes em situação de violência sexual, os estudos sobre o tema já conseguiram avançar em alguns aspectos. Sendo assim, ressalta-se que, devido a sua complexidade, qualquer intervenção relativa à violência sexual infanto-juvenil deve dar-se através de uma rede articulada de instituições que possibilitem uma ação integrada. Além disso, é primordial que toda criança ou adolescente seja tratado com total respeito, pois não se pode esquecer que estamos diante de indivíduos que tiveram seu corpo violado e, na maioria das vezes, sua inocência roubada.

\section{Método}

A presente pesquisa foi realizada no Programa Sentinela, da cidade de Blumenau/SC, e caracteriza-se como um estudo exploratório de caráter descritivo que, segundo Gil, tem “(...) como objetivo primordial a descrição das características de determinada população ou fenômeno (...)" (2002, p. 42). Dadas, por um lado, a especificidade da investigação e, por outro, as questões éticas que envolvem a violência sexual infanto-juvenil, a opção metodológica empregada na investigação foi a análise documental, tendo sido utilizada a abordagem quantitativa-qualitativa, que permitiu a interpretação e a mensuração dos dados.

O Sentinela é um programa federal de proteção social especial de média complexidade, e abrange 1104 dos 5565 Municípios brasileiros. O programa foi instituído pelo Governo brasileiro em 2001, com o objetivo de prestar atendimento a crianças e adolescentes vítimas de violência física, abuso/violência sexual, violência psicológica e negligência. A ênfase do programa está no abuso e na exploração sexual (Comitê Nacional de Enfrentamento à Violência Sexual contra Crianças e Adolescentes, 2006). 
Em 2006, com a implantação do Sistema Único de Assistência Social (SUAS), o Sentinela passou a ser compreendido como serviço de média complexidade do Centro de Referência Especial de Assistência Social (CREAS), que obedece às Normas Operacionais Básicas da Política Pública de Assistência Social, e tornou-se um serviço de ação continuada (Conselho Federal de Psicologia, 2009). Atualmente, denomina-se Serviço de Proteção e Atendimento Especializado a Famílias e Indivíduos (Paefi), e destina-se ao atendimento de indivíduos e famílias em situações de violação de direitos, como violência (física, psicológica e negligência, abuso e/ou exploração sexual), tráfico de pessoas, situação de rua, mendicância, abandono, vivência de trabalho infantil, discriminação em decorrência da orientação sexual ou raça/etnia e outras formas de violação de direitos decorrentes de discriminações ou de submissões (Conselho Nacional de Assistência Social, 2009).

No entanto, em Blumenau, o programa que foi implantado como Centro de Referência, no mês de setembro de 2005, continua com a denominação Sentinela, e atende cerca de 285 crianças e adolescentes por mês, através de uma equipe de 10 profissionais das áreas de serviço social, Psicologia e Pedagogia (Prefeitura Municipal de Blumenau, 2009).

A população total envolvida na pesquisa foi composta por 30 crianças e adolescentes que sofreram violência sexual e que foram atendidos pelo Programa Sentinela. Essa população foi estudada a partir da análise de seus prontuários de atendimento. A amostra foi intencional, e os requisitos de inclusão foram: ser prontuário de criança ou adolescente (faixa etária de zero a 18 anos), conter notificação de violência sexual e a criança ou o adolescente atendido ter sido desligado do programa no segundo semestre de 2009.

Para a coleta de dados, foi elaborado um protocolo de investigação pré-estabelecido, o qual permitiu a coleta das informações referentes à atuação do Programa Sentinela na cidade de Blumenau/SC. Essas informações compreendiam os seguintes dados: pessoa ou instituição que realizou a denúncia, instituição ou órgão de primeiro contato, intervalo entre denúncia e primeiro atendimento, procedimentos realizados com a criança ou adolescente, procedimentos realizados com o autor da violência, outras intervenções realizadas pelo programa, encaminhamentos feitos pelo Sentinela, profissionais que atuaram na situação, tempo de acompanhamento da família, motivo de desligamento, planejamento das intervenções e ocorrência de avaliação inicial da criança ou adolescente. Assim, a coleta de dados se efetivou pelo preenchimento do protocolo de investigação com as informações contidas nos prontuários.

Para tanto, efetuou-se a leitura dos prontuários, incluindo os atendimentos realizados em cada situação. A análise dos dados foi realizada com base em uma abordagem qualitativa de análise de conteúdo, conforme proposto por Bardin (1977). De acordo com Engers (1994), a análise de conteúdo se caracteriza por um conjunto de instrumentos e técnicas utilizados na análise e na interpretação de dados de uma pesquisa, que são aplicados, principalmente, em pesquisas de documentos escritos, discursos e semelhantes, com o objetivo de se fazer uma leitura crítica e aprofundada, que proporcione a descrição e a interpretação desse material. Dessa forma, a primeira fase do processo de análise incluiu a leitura dos prontuários selecionados na íntegra, de modo a destacar e a selecionar os aspectos relevantes presentes nesses documentos para se atingir os objetivos da pesquisa. Na etapa de exploração do material e de tratamento dos resultados, houve a categorização dos dados em unidades temáticas, conforme protocolo de investigação. Uma vez identificados os temas principais, foi realizada a interpretação dos resultados dessa análise, buscando-se apreender o modo de atuação do Programa Sentinela frente à violência sexual infanto-juvenil. 
Por fim, os dados foram analisados quantitativamente com auxílio do Microsoft Excel e distribuídos em gráficos e tabelas com frequências e porcentagens, para melhor compreensão dos resultados.

Vale ressaltar que, por envolver dados pessoais e privativos de crianças e adolescentes, a coleta de dados foi condicionada à obtenção da autorização da coordenadora do Projeto Sentinela e à assinatura do Termo de Responsabilidade pelos pesquisadores, garantindo-se os cuidados éticos necessários para a elaboração da pesquisa.

\section{Resultados}

\section{Características das situações de violência sexual}

A análise dos dados coletados demonstrou que, na maioria dos casos, a violência sexual foi denunciada por algum membro da família da criança ou adolescente (Gráfico 1), sendo a mãe responsável pela denúncia em 50\% dos casos, e os pais (mãe e pai juntos), em $14 \%$.

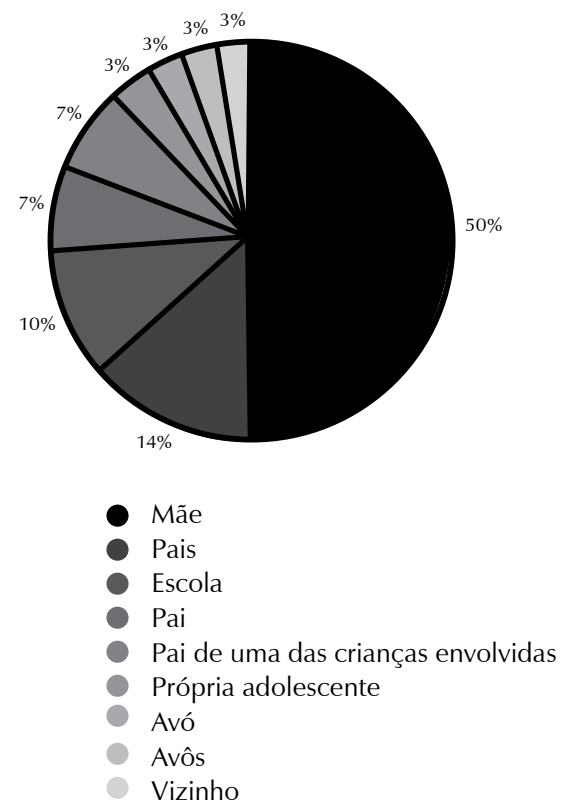

Gráfico 1. Pessoa ou instituição que realizou a denúncia
O principal órgão do qual procederam os encaminhamentos para o Programa Sentinela foi o Conselho Tutelar, responsável por $73 \%$ dos encaminhamentos para o programa, sendo que $40 \%$ deles procederam do Conselho Tutelar do Centro, e 33\%, do Conselho Tutelar do Garcia. Os encaminhamentos, igualmente, procederam da DPMCA (14\%), da polícia civil (7\%), do Disque 100 (3\%) e do Aviso por Maus-Tratos contra Criança ou Adolescente (APOMT) (3\%).

Em relação ao autor da violência, verifica-se que, em $36 \%$ dos casos, a idade do autor da violência era desconhecida ou não constava nos prontuários. Dos casos nos quais a idade do abusador foi identificada, 28\% das situações foram provocadas por adultos (entre 25 a 59 anos), 25\% por adolescentes (entre 12 a 17 anos), 5\%, por crianças (entre 10 a 11 anos), 3\%, por jovens (entre 18 a 24 anos) e $3 \%$, por idosos (igual ou superior a 60 anos).

\section{Aspectos de assistência e vulnerabilidade do Programa Sentinela}

Nesta seção, serão apresentados os dados relacionados ao funcionamento do Programa Sentinela, identificando os fatores de assistência e de vulnerabilidade do programa. Nesse sentido, os aspectos de assistência do Sentinela são as ações que auxiliam, de maneira eficaz, a criança ou o adolescente em situação de violência sexual, bem como suas famílias, a superar a violência sofrida. Por outro lado, os aspectos de vulnerabilidade referem-se aos fatores de riscos do programa, que dificultam a superação da violência sexual e/ou podem ocasionar um dano secundário para a criança ou para o adolescente e suas famílias.

O Gráfico 2 apresenta o intervalo de tempo entre denúncia da violência sexual e realização do atendimento pelo programa. 
Como podemos constatar, na maior parte dos casos, a criança ou o adolescente demorou entre 0 a 15 dias ou entre 15 a 30 dias para receber o primeiro atendimento após a revelação do abuso.

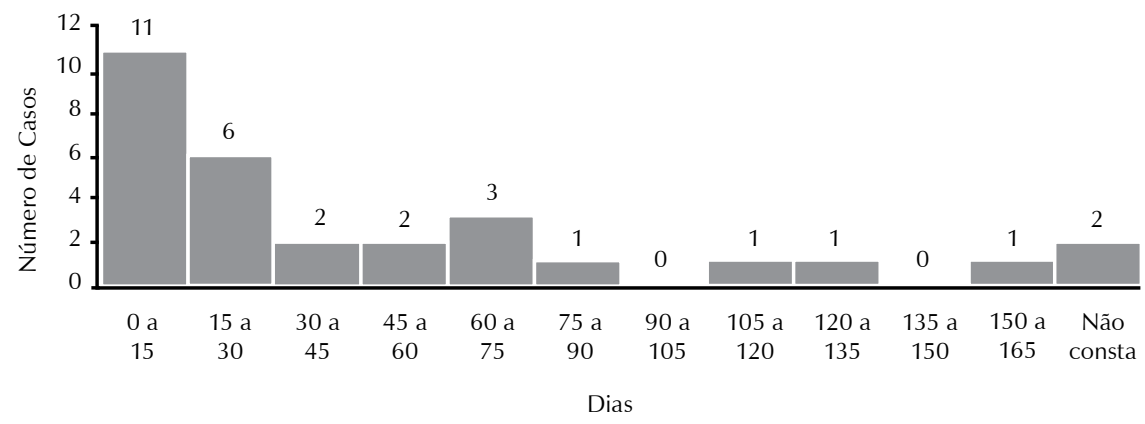

Gráfico 2. Intervalo de tempo entre denúncia e primeiro atendimento

Em 100\% dos casos pesquisados, foi primeiramente realizado acolhimento com a criança ou adolescente e suas famílias, que tinha como objetivo principal o estabelecimento de vínculo, a orientação sobre o programa e as metodologias utilizadas e o esclarecimento sobre o motivo de encaminhamento. Observou-se que os acolhimentos se davam em um ambiente protetor, onde a criança ou adolescente poderiam expressar-se livremente e tirar suas dúvidas em relação ao programa. Nesse primeiro momento, não eram realizadas perguntas pertinentes à situação abusiva, sendo que a criança ou o adolescente relatava o abuso apenas se fosse de sua vontade.

No que se refere à avaliação inicial, em nenhum dos prontuários consta se ela ocorreu ou não, porém, em $90 \%$ dos prontuários, há relatos das consequências que a violência sexual teve para a criança ou adolescente. Tal fator pode indicar a ocorrência de uma avaliação inicial.

Os tipos de atendimento que decorreram da realização do acolhimento foram o atendimento psicossocial, o psicológico e o psicoeducativo (Gráfico 3). Observa-se que com maior frequência as crianças ou adolescentes receberam mais de um tipo de atendimento, havendo prevalência da realização de atendimento psicossocial e psicológico com a mesma criança ou adolescente, que foi realizado em $33 \%$ dos casos estudados.

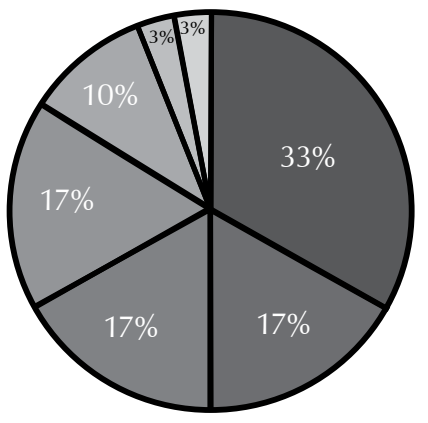

Psicossocial e Psicológico

Apenas acolhimento

Somente psicossocial

Psicosocial, psicológico e psicoeducativo

Somente psicológico

Psicossocial e psicoeducativo

Psicológico e psicoeducativo

Gráfico 3. Tipos de atendimentos realizados pelo Programa Sentinela da cidade de Blumenau 
Entre as modalidades de tratamento, estão a terapia familiar, a individual e com os pais. A terapia familiar foi a modalidade de maior incidência (47\%), seguida pela utilização da terapia familiar, individual e com os pais no mesmo caso (30\%) e terapia individual e familiar no mesmo caso (14\%). Além dessas, observa-se a ocorrência da terapia individual e com os pais, da terapia familiar e com os pais e a realização apenas da modalidade individual, ambas com frequência de $3 \%$.

Outras medidas promovidas pelo Sentinela foram: contato telefônico com a família da criança ou do adolescente, visita domiciliar, visita à escola da criança ou do adolescente ou contato com essa instituição de ensino, orientações judiciais, contato com a DPMCA, contato e reunião com o Centro de Atenção Psicossocial Infanto-Juvenil (CAPSI), contato com o Centro de Referência de Assistência Social (CRAS) e com o Conselho Tutelar. Essas medidas foram realizadas em 24 dos 30 casos, e estão distribuídas conforme a Tabela 1.

O contato telefônico com a família da criança ou do adolescente teve o objetivo de agendar o atendimento ou de informar sobre a sua ausência nos atendimentos pré-agendados. Nos casos em que não foi possível contato pelo telefone, foi realizada a visita domiciliar, que foi, também, utilizada com o propósito de verificar o meio no qual a criança está inserida, levantando-se questões socioeconômicas e de proteção da criança ou do adolescente.

Tabela 1. Outras intervenções realizadas pelo Programa Sentinela da cidade de Blumenau/SC

\begin{tabular}{lcc}
\hline Intervenção & Freq. Absoluta & Freq. Relativa \% \\
\hline Contato telefônico com a família da criança ou adolescente & 12 & 25 \\
Contato telefônico com a DPMCA & 1 & 2 \\
Contato telefônico e reunião com a CAPSI & 1 & 2 \\
Contato telefônico com o CRAS & 1 & 2 \\
Contato telefônico com o Conselho Tutelar & 1 & 2 \\
Contato telefônico com a escola da criança ou adolescente & 4 & 9 \\
Orientações judiciais & 4 & 9 \\
Visita domiciliar & 17 & 36 \\
Visita a escola da criança ou adolescente & 6 & 13 \\
TOTAL & 47 & 100
\end{tabular}

Para maior efetividade do tratamento, o Programa Sentinela realizou encaminhamentos para outras instituições em 16 dos 30 casos pesquisados. A instituição que recebeu maior número de encaminhamentos foi o Programa Saúde da Família (PSF), com (32\%) dos encaminhamentos, que atendeu as questões médicas relacionadas com a criança ou o adolescente e suas famílias. As famílias, igualmente, foram encaminhadas para a Secretaria de Assistência Social da Criança e do Adolescente (SEMASCRI), em 17\% dos encaminhamentos, e para o CAPSI, com 11\%, atendendo as questões sociais e de saúde mental, respectivamente. Os outros encaminhamentos foram para atendimento pedagógico, avaliação neurológica, defesa civil, Programa Pró-Trabalhador, Programa Egresso, Diretoria de Articulação, Reinserção Profissional e Captação de Recursos, DPPMCA e Pronto Atendimento Médico, ambos com $5 \%$ de frequência.

Ressalta-se, todavia, que em nenhum dos prontuários consta o relato do planejamento das intervenções realizadas com a criança ou o adolescente e com suas famílias no que tange ao tipo e à modalidade de atendimento que seriam utilizados, bem como aos encaminhamentos e às medidas necessários para a superação da violência, o que sugere o não planejamento das intervenções por parte das equipes do Programa Sentinela. 
As intervenções foram realizadas, geralmente, por uma equipe interdisciplinar que envolvia psicólogo e assistente social em $83 \%$ dos casos. Contudo, em alguns casos, verifica-se apenas a atuação do psicólogo (10\%) ou do assistente social (7\%).

Outro fator relevante é que, em $87 \%$ dos casos, não houve nenhuma intervenção com o autor da violência. Em dois casos, a pessoa que cometeu a violência sexual teve como medida punitiva a prisão, e apenas dois dos autores da violência sexual receberam alguma forma de tratamento terapêutico, em que se realizou o aconselhamento em uma das situações e o atendimento psicossocial familiar em outra.

Os motivos pelos quais as crianças e os adolescentes foram desligados do Programa Sentinela estão distribuídos no Gráfico 4. Em sete dos casos, foi relatado mais de um motivo, e o mais frequente foi que a criança ou adolescente se encontrava com seus direitos garantidos, aparecendo em 23 dos casos analisados, porém, em nenhum dos casos foram descritos os critérios utilizados para tal afirmação.


Gráfico 4. Motivos de desligamento do Programa Sentinela da cidade de Blumenau/SC

Em relação ao tempo de permanência no Programa Sentinela, o Gráfico 5 demonstra que o tempo durante o qual as crianças e adolescentes receberam tratamento no programa variou entre 1 a 660 dias. Os tempos prevalentes foram de 330 a 440 dias (em 8 casos), de 110 a 220 (em 7 casos) e de 1 a 110 dias (em 6 casos).

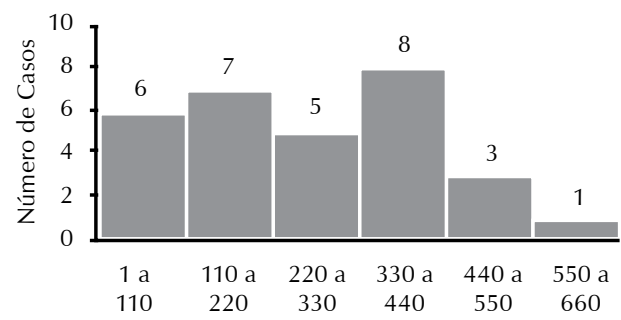

Gráfico 5. Tempo de permanência no Programa Sentinela da cidade de Blumenau/SC

Em todos os casos, houve acompanhamento do Conselho Tutelar, que foi realizado através de trocas de relatórios. Assim, o desfecho de cada caso deu-se através do encaminhamento ao Conselho Tutelar de um relatório referente à situação atual da criança ou adolescente, procedimentos realizados pelo Sentinela e motivo de desligamento.

Percebe-se, enfim, a ausência de informações em alguns prontuários. Tal fator comprometeu a análise de algumas variáveis, especialmente no que se refere às informações sobre a realização ou não da 
avaliação inicial da criança ou adolescente, o planejamento das intervenções e as técnicas e os critérios utilizados pelo profissional para avaliar o desligamento da criança ou adolescente do programa. Observou-se, ainda, a falta de uniformidade nos dados, visto que em alguns casos os atendimentos foram relatados apenas de maneira sucinta.

\section{Discussão}

O notificante é o elemento que torna pública a violência, e pode ser considerado um ator importante na rede de proteção à criança. $\mathrm{O}$ presente trabalho constatou que, em $50 \%$ dos casos, a mãe foi o notificante, e os pais (mãe e pai juntos) o foram em 14\% dos casos. Dados semelhantes foram encontrados por Habigzang et al (2005). Em sua pesquisa sobre violência sexual, os autores também constataram que a violência sexual foi denunciada com maior frequência pela mãe da criança ou do adolescente $(37,6 \%$ dos casos) e por outros parentes $(15,1 \%)$. Nesse sentido, o elevado percentual de notificação por pessoas com algum vínculo familiar com a criança ou adolescente sugere quão difícil é para a sociedade apresentar denúncias de situações de suspeita ou de confirmação de violência sexual. Percebe-se, assim, que a violência sexual ainda é vista como um tabu e um escândalo social, pertencente ao meio familiar no qual ela ocorre e de responsabilidade desse mesmo meio.

Em relação ao órgão ou instituição de procedência dos encaminhamentos ao Programa Sentinela, observou-se que o programa recebeu denúncias de abuso sexual advindas do Conselho Tutelar, da polícia civil, do APOMT, do Disque 100 e da DPMCA, o que demonstra a credibilidade que vem sendo conquistada por esse programa. Entretanto, a maioria dos encaminhamentos procedeu do Conselho Tutelar. Outros estudos, do mesmo modo, destacam esse órgão como o principal órgão de encaminhamento ou de primeiro contato. Ferriani, Garbin e Ribeiro (2004), em pesquisa realizada em Ribeirão Preto/SP, relatam que o
Conselho Tutelar foi o meio mais utilizado para a realização das denúncias. Igualmente, Baptista, Brito, Costa e França (2008) descrevem que 68\% dos casos de abuso sexual infanto-juvenil foram notificados pelo Conselho Tutelar em estudo realizado em Campina Grande/PB.

Tal fator, além de representar a obrigatoriedade, instituída pelo Estatuto da Criança e do Adolescente (ECA), da notificação de casos de violência sexual ao Conselho Tutelar, é reflexo do modo de funcionamento do Programa Sentinela, pois, de acordo com as diretrizes de funcionamento do programa, este "deve receber os casos encaminhados pelo Conselho Tutelar do Município para análise e estudo da situação" (Ministério do Desenvolvimento Social, 2006, p. 5). Esse dado também denota a importância que o Conselho Tutelar ocupa na rede e na comunidade na qual está inserido.

Após a revelação do abuso sexual, é importante que a criança ou adolescente envolvido na situação e sua família recebam alguma forma de intervenção o mais rápido possível, já que, conforme Furniss (1993), a revelação do abuso sexual contra a criança conduz a uma crise imediata nas famílias, visto que a simples nomeação do abuso estabelece o abuso como um fato para a criança e sua família. Nesse contexto, durante a análise dos dados, observouse que $37 \%$ dos casos notificados levaram até quinze dias para receber atendimento. Já na literatura de apoio não foram detectados estudos que mencionassem o intervalo de tempo entre denúncia e atendimento. No entanto, visto o fator de risco que o abuso sexual representa, apesar de a maior parte dos casos pesquisados ter recebido atendimento em tempo hábil, esse número ainda não é expressivo. Dessa forma, é relevante que o Sentinela continue a trabalhar para aumentar o número de casos em que há um pequeno intervalo de tempo entre revelação do abuso e primeiro atendimento.

A literatura aponta o acolhimento como parte primordial do atendimento, sendo ele importante para estabelecer um vínculo com a criança e o adolescente, e deve ser realizado 
livre de preconceitos e sem interrupções ou solicitações de detalhamento desnecessário (Pfeiffer \& Salvagni, 2005; Habigzang, 2006). Desse modo, a realização de acolhimento em todos os casos pesquisados, sendo ele realizado em um ambiente protetor, onde a criança ou adolescente poderiam expressar-se livremente, representa um dos fatores de assistência do Programa Sentinela.

Com base nos resultados do presente estudo, as crianças e adolescentes em situação de violência sexual atendidas pelo Programa Sentinela receberam com maior frequência mais de uma forma de tratamento, destacandose o atendimento psicossocial e psicológico. Lueneberg, Machado, , Régis e Nunes (2005), igualmente, verificaram que o tipo predominante de atendimento prestado a crianças e adolescentes em situação de violência sexual é o psicossocial (26,80\%).

Além disso, na escolha ao tipo de atendimento, a literatura destaca os atendimentos psicológicos, psicossociais e psicoeducativos (Saywitz et. al., 2000). De acordo com a análise dos resultados, esses tipos de atendimento são prestados pelo Programa Sentinela, o que indica um fator de assistência do programa. Contudo, nos casos pesquisados, não se observa um planejamento relativo ao tipo de atendimento que será utilizado. De acordo com Saywitz et. al., a escolha do tipo de atendimento depende da avaliação inicial da criança ou do adolescente; o não planejamento da escolha do tratamento é, portanto, um fator de vulnerabilidade do Sentinela.

Como previsto nas diretrizes de funcionamento do Sentinela, os atendimentos são feitos na modalidade familiar, individual e com os pais. Habigzang (2006) e Saywitz et al. (2000) ressaltam, como já apontamos, que é necessário realizar tratamentos em diferentes modalidades para diferentes crianças ou para a mesma criança em diferentes tempos, o que indica um fator de assistência do programa.
Destaque-se, todavia, que a literatura ressalta a modalidade grupal como excelente modalidade na redução das consequências advindas da violência sexual (Mcgain \& Mckinzey 1995; Seixas, 1999; Habigzang, 2006). Entretanto, essa modalidade não é realizada pelo Sentinela. Assim, sugere-se, como medida que possa contribuir para a qualificação do programa, a introdução da modalidade grupal nos atendimentos realizados.

Por outro lado, a realização de tratamento com a família da criança ou adolescente em situação de violência sexual representa um fator de assistência do programa, pois o tratamento familiar é apontado como essencial para desenvolver um plano de tratamento significativo (Furniss, 1993; Saywitz et al., 2000; King et al., 2000, Saunders, Berliner, \& Hanson., 2004).

Além dessas, o Sentinela promove outras medidas de intervenção, como contato telefônico e visita domiciliar em caso da ausência da criança ou adolescente nos atendimentos pré-agendados. Tais medidas representam uma não negligência por parte do programa com as famílias em atendimento. A visita domiciliar, também utilizada com o propósito de verificar o meio no qual a criança está inserida, é outro aspecto importante, uma vez que a coexistência de diferentes formas de violência em caso de abuso sexual tem sido frequentemente apontada pelos pesquisadores da área (Cohen \& Mannarino, 2000; Habigzang \& Caminha, 2004; Kellog \& Menard, 2003).

Entre as outras formas de intervenção, destacase, do mesmo modo, a realização de orientações judiciais feitas pelos profissionais do programa às famílias em atendimento. Observa-se, desse modo, que os profissionais do Sentinela, em seus atendimentos, unem os domínios legais, de saúde e de saúde mental, fator de extrema relevância para que se evite o processo de revitimização (Furniss, 1993; Amazarray \& Koller, 1998). 
Conforme as diretrizes de funcionamento do programa, este deve manter estreita articulação com os demais serviços de proteção social básica e especial, com as demais políticas públicas e instituições que compõem o Sistema de Garantia de Direitos (Ministério do Desenvolvimento Social, 2006). Observase, no presente estudo, que essa articulação é feita através de encaminhamentos para outras instituições, porém, com exceção do Conselho Tutelar, o programa realizou contato com as instituições que compõem o Sistema de Garantia de Direitos em apenas 3 dos 19 encaminhamentos realizados. Percebe-se, assim, a falta de uma ação articulada, o que representa um fator de vulnerabilidade do programa.

Além desse, outro fator de vulnerabilidade do Sentinela é a não realização, em $87 \%$ dos casos, de intervenção com o autor da violência, fato esse de extrema gravidade, já que, em 30\% dos casos estudados, o autor da violência tinha entre 10 e 17 anos. Furniss (1993) ressalta a necessidade dessa intervenção, como forma de se compreender e de prevenir a violência sexual. Outro fato ao qual devemos dar suma importância é a impunidade com que a violência sexual é tratada no Brasil, pois em apenas dois casos a pessoa que cometeu a violência sexual teve como medida punitiva a prisão.

Nas diretrizes de funcionamento do Sentinela, constata-se que o programa deve contar com equipe de profissionais que trabalhem de maneira interdisciplinar, o que pudemos verificar a partir do estudo realizado, pois grande parte dos atendimentos foram realizados por psicólogos e assistentes sociais.

Durante a análise dos dados, verificou-se, como fator de assistência, o fato de que, de maneira geral, os casos de atendimento somente foram desligados do programa com a constatação de que a criança ou adolescente se encontrava com seus direitos garantidos. Outro fator de assistência é o acompanhamento do Conselho Tutelar, realizado através de trocas de relatórios entre as duas instituições. Conforme as diretrizes do programa, "(...) esgotadas todas as possibilidades de intervenção, sem mudança dos padrões violadores de direitos, a autoridade competente deverá ser informada por meio de relatório circunstanciado, para que sejam tomadas as medidas pertinentes" (Ministério do Desenvolvimento Social, 2006, p. 20), o que efetivamente ocorre no contexto estudado.

Em relação ao tempo de permanência no Programa Sentinela, o estudo demonstrou que a maioria das crianças e adolescentes receberam tratamento no programa durante 1 ano e 3 meses. Na literatura utilizada, não localizamos dados sobre o tempo médio de permanência na instituição.

No processo de análise, percebeu-se, por fim, que algumas fichas apresentavam ausência de informações, o que representa um fator de vulnerabilidade do programa, uma vez que, conforme a Organização Mundial de Saúde (2003) é de extrema importância documentar todas as informações. No mais, Lueneberg, Machado, Régis, e Nunes (2005) afirmam que um fator importante para a prevenção desse tipo de violência é o preenchimento correto e completo dos dados que compõem a ficha de atendimento, pois, se ela estiver incompleta, poderá dificultar a assistência e impedirá o diagnóstico precoce dos fatores de risco para possível prevenção da violência sexual. Como sugestão, fica a descrição dos critérios de desligamento e da avaliação inicial em cada protocolo, justificando-os de maneira detalhada.

\section{Conclusões}

As informações sobre os casos de violência sexual contra crianças e adolescentes coletadas a partir da análise dos prontuários disponíveis no Programa Sentinela, da cidade de Blumenau/SC, permitiram compreender a atuação do Sentinela frente ao abuso sexual e identificar os fatores de assistência e de vulnerabilidade envolvidos no seu contexto. Do mesmo modo, possibilitaram observar a impunidade com que a questão da violência sexual é tratada no Brasil e o tabu que cerca essa violência. 
Os resultados revelam que o Sentinela, de maneira satisfatória, consegue cumprir seu objetivo de prestar atendimento às crianças e adolescentes em situação de violência sexual, bem como aos seus familiares. Para tanto, o programa atua em uma rede integrada com o Conselho Tutelar, prestando atendimento aos casos notificados no Conselho. Ao chegar ao Sentinela, primeiramente é realizado um acolhimento com a criança ou adolescente em situação de violência sexual e sua família, estabelecendo-se vínculos e esclarecendose a metodologia de trabalho. Em seguida, são proporcionados atendimentos a essas crianças e adolescentes, dentre os quais estão os atendimentos psicológicos, psicossociais e psicoeducativos, realizados na modalidade individual ou familiar. Quando necessário, para maior efetividade do tratamento, o Sentinela realiza encaminhamentos para outras instituições de garantia de direitos da criança e do adolescente, que são desligados do programa quando se encontram com seus direitos garantidos, permanecendo em média 1 ano e 3 meses no programa. Ao ser realizado o desligamento das crianças e adolescentes, o Conselho Tutelar é informado através de um relatório.

A análise dos documentos ainda possibilitou o mapeamento de fatores de assistência e de vulnerabilidade do Programa Sentinela no atendimento de criança ou adolescente em situação de violência sexual. Nesse contexto, entre os fatores de assistência identificados, destacam-se: a credibilidade do programa, a realização de acolhimento em um ambiente de total respeito à criança ou adolescente, a variedade de tipos e de modalidades de atendimento utilizados, o atendimento com os cuidadores da criança ou do adolescente, a insistência para que a família compareça aos atendimentos, a verificação do meio no qual a criança ou adolescente está inserido (visita domiciliar), a articulação entre domínios legais, de saúde e de saúde mental, o desligamento do programa somente após a garantia dos direitos da criança ou do adolescente e as trocas de informações (laudos e relatórios) com o Conselho Tutelar.

Por outro lado, os fatores de vulnerabilidade do programa foram: não planejamento das intervenções, não realização de intervenção com o autor da violência, a falta de uma ação articulada entre o programa, os serviços de proteção social básica e especial, as demais políticas públicas e instituições que compõem o Sistema de Garantia de Direitos da criança e do adolescente e a ausência de informação em alguns prontuários, principalmente na avaliação inicial e na descrição dos critérios sociais e psicológicos de desligamento.

Sugere-se, por fim, como medida para qualificação do Sentinela, a introdução da modalidade grupal nos atendimentos, uma vez que a grupoterapia tem apresentado resultados relevantes no tratamento de crianças e adolescentes em situação de violência sexual (Mcgain \& Mckinzey, 1995; Seixas, 1999; Cohen \& Mannarino, 2005; Habigzang, 2006).

Diante do exposto, verificamos que o presente estudo conseguiu atingir seus objetivos, identificando a atuação do Programa Sentinela e mapeando os fatores de assistência e de vulnerabilidade do programa. Assim sendo, observou-se que o Sentinela constitui uma ferramenta contra a violência sexual, entretanto, possui alguns pontos que necessitam ser otimizados.

Glauco Anderson Espindola

Especialista em Metodologias de Atendimento a Criança e ao Adolescente em Situação de Risco pela Universidade do Estado de Santa Catarina, Blumenau- SC - Brasil.

E-mail: glaucopsi@gmail.com

Vanderléia Batista

Psicóloga formada pela Fundação Universidade Regional de Blumenau, Blumenau - SC - Brasil.

E-mail: letista19@hotmail.com

Endereço para envio de correspondência:

Rua Harry Wruck, no 61, Fortaleza. CEP: 89056-210. Blumenau, SC.

Recebido 12/12/2011, 1프 Reformulação 04/04/2013, Aprovado 11/04/2013. 


\section{Referências}

Associação Brasileira de Proteção à Infância e à Adolescência. (2002). Abuso sexual: mitos e realidade - por que?! Quem?! Como?! O Quê?! Rio de Janeiro: Autores e Agentes Associados.

Alzuguir, F. C. V., Assis, S. G., \& Souza, E. R. (2002). Estratégias de atendimento aos casos de abuso sexual infantil: um estudo bibliográfico. Revista Brasileira de Saúde Materna Infantil, 2, 105-116.

Amazarray, M. R., \& Koller, S. H. (1998). Alguns aspectos observados no desenvolvimento de crianças vítimas de abuso sexual. Psicologia, Reflexão e Crítica, 11, 559-78.

Arboleta, M. R. C., \& Duarte, J. C. (2005). Sintomatologia, avaliação e tratamento do abuso sexual infantil. In V. E. Caballo \& M. Á. Simón. Manual de psicologia clínica infantil e do adolescente - transtornos gerais (pp. 293-321). São Paulo: Editora Santos.

Baptista, R. S., Brito, V. R. de S., Costa, C. M. P., \& França, I. S. X. (2008). Caracterização do abuso sexual em crianças e adolescentes notificado em um Programa Sentinela. Acta Paul Enferm., 21(4), 602-608.

Bardin, L. (1977). Análise de Conteúdo. Lisboa: Edições 70.

Cohen, J. A., \& Mannarino, A. P. (2000). Predictors of treatment outcome in sexually abused children. Child Abuse \& Neglect, 24, 983-994.

Cohen, J. A., Mannarino, A. P., \& Knudsen, K. (2005). Treating sexually abused children: One year follow-up of a randomized controlled trial. Child Abuse \& Neglect, 29, 135145 .

Comitê Nacional de Enfrentamento à Violência Sexual contra Crianças e Adolescentes. (2006). Plano Nacional de Enfrentamento da Violência Sexual Infanto-juvenil - uma política em movimento (Relatório do monitoramento 20032004). Brasília, DF.

Conselho Federal de Psicologia. (2009). Serviço de Proteção Social a Crianças e Adolescentes Vítimas de Violência, Abuso e Exploração Sexual e suas Famílias: referências para a atuação do psicólogo. Brasília, DF.

Conselho Nacional de Assistência Social. (2009). Tipificação Nacional de Serviços Socioassistenciais. Brasília, DF.

Delegacia de Proteção à Mulher e ao Adolescente de Blumenau. (2009). Relatório anual de 2006/2007/2008. Secretaria de Segurança Pública e Defesa do Cidadão. Blumenau, SC.

Engers, M. E. (1994). Paradigmas e Metodologias de Pesquisa em Educação: Notas para Reflexão. Porto Alegre: EDIPUCRS.

Ferreira, A. L., \& Gonçalves, H. S. (2002). A notificação da violência intrafamiliar contra crianças e adolescentes por profissionais da saúde. Caderno de Saúde Pública, 18(1), 315-319.

Ferriani, M. G. C., Garbin, L. M. \& Ribeiro, M. A. (2004). Caracterização de casos em que crianças e adolescentes foram vítimas de abuso sexual na região sudoeste da cidade de Ribeirão Preto, SP, no ano 2000. Acta Paul Enferm., 17(1), 45-54.

Furniss, T. (1993). Abuso sexual da criança: uma abordagem multidisciplinar. Porto Alegre: Artes Médicas.

Gil, A. C. (2002). Como elaborar projetos de pesquisa (4a. ed.). São Paulo: Editora Atlas S.A.

Habigzang, L. F., \& Caminha, R. M. (2004). Abuso sexual contra crianças e adolescentes: conceituação e intervenção clínica. São Paulo: Casa do Psicólogo.

Habigzang, L. F., Koller, S. H., Azevedo, G. A., \& Machado, P. X. (2005). Abuso sexual infantil e dinâmica familiar: aspectos observados em processos jurídicos. Psicologia: Teoria e Pesquisa, 21(3), 341-348.
Habigzang, L. F. (2006). Avaliação e intervenção psicológica para meninas vítimas de abuso sexual intrafamiliar. (Dissertação de Mestrado). Instituto de Psicologia, Universidade Federal do Rio Grande do Sul, Porto Alegre, RS.

Habigzang, L. F, Azevedo, G. A, Koller, S. H., \& Machado, P. X (2006). Fatores de risco e de proteção na rede de atendimento a crianças e adolescentes vítimas de violência sexual. Psicologia: Reflexão e Crítica, 19(3), 379-386.

Kellog, N. D., \& Menard, S. W. (2003). Violence among family members of children and adolescents evaluated for sexual abuse. Child Abuse \& Neglect, 27, 1367-1376.

King, N. J., Tonge, B. J., Mullen, P., Myerson, N., Heyne, D., \& Rollings, S. et al. (2000). Treating sexually abused children with posttraumatic stress symptoms: A randomized clinical trial. Journal of the American Academy of Child and Adolescent Psychiatry, 39, 1347-1355.

Lueneberg, C. F., Machado, H. B., Régis, E. I., \& Nunes, M. P. P. (2005). Abuso sexual: diagnóstico de casos notificados no Município de Itajaí/SC, no período de 1999 a 2003, como instrumento para a intervenção com famílias que vivenciam situações de violência. Texto Contexto Enfermagem, 14 (Esp.), 54-63.

Mcgain, B., \& Mckinzey, R. K. (1995). The efficacy of group treatment in sexually abused girls. Child Abuse \& Neglect, 19, 1157-1169.

Ministério do Desenvolvimento Social. (2006). Programa sentinela. Recuperado em 10 outubro, 2009, de http://www. mds.gov.br/programas/rede-suas/protecao-social-especial/ programa-sentinela-protecaosocial-as-criancas-adolescentesvitimas-de-violencia.

Pfeiffer, L., \& Salvagni, E. P. (2005). Visão atual do abuso sexual na infância e adolescência. Jornal de Pediatria, 81(5), 197-204.

Prefeitura Municipal de Blumenau. (2009). Semascri promove ações de conscientização na Semana Estadual de Combate ao Abuso e à Exploração Sexual Infanto-juvenil, a partir desta terça, 22. Recuperado em 30 outubro, 2009, de http://www.blumenau. sc.gov.br/novo/site/noticia/index.php?codigo $=25697$

Pereda, N., Polo, P., Grau, N., Navales, N., \& Martínez, M. (2007). Víctimas de abuso sexual en la infancia. Estudio descriptivo. Revista d'Estudis de la Violênci, 1, 1-18. Recuperado em 20 agosto, 2009, de http:// www.icev.cat

Saunders, B. E., Berliner, L., \& Hanson, R. F. (2004). Child physical and sexual abuse: Guidelines for treatment. Charleston: National Crime Victims Research and Treatment Center. Recuperado em 30 outubro, 2009, de http://academicdepartments.musc.edu/ ncvc/resources_prof/ovc_guidelines04-26-04.pdf

Saywitz, K. J., Mannarino, A. P., Berliner, L., \& Cohen, J. A. (2000). Treatment for sexually abused children and adolescents. American Psychologist, 55(9),1040-1049.

Seixas, A. H. (1999). Abuso sexual na adolescência. In N. Schor, M. do S. F. T. Mota \& V. C. Branco. Cadernos Juventude, Saúde e Desenvolvimento (pp. 117-135). Brasília, DF: Ministério da Saúde.

World Health Organization. (2003). Guidelines for medico-legal care for victims of sexual violence. Recuperado em 20 julho, 2009, de http://www.who.int/violence_injury prevention/ publications/violence/med_leg_guidelines/en/index.htm 